\title{
Branched multipeptide immunotherapy for glioblastoma using human leukocyte antigen-A*0201-restricted cytotoxic T-lymphocyte epitopes from ERBB2, BIRC5 and CD99
}

\author{
Young-Hee Kim¹, Thi-Anh-Thuy Tran', Hyun-Ju Lee ${ }^{2}$, Sook-In Jung ${ }^{3}$, Je-Jung \\ Lee $^{2,4}$, Wool-Youl Jang ${ }^{1,5}$, Kyung-Sub Moon ${ }^{1,5}$, In-Young Kim ${ }^{1,5}$, Shin Jung ${ }^{1,5}$, Tae- \\ Young Jung ${ }^{1,5}$ \\ ${ }^{1}$ Brain Tumor Research Laboratory, Chonnam National University Hwasun Hospital, Chonnam, Republic of Korea \\ ${ }^{2}$ Research Center for Cancer Immunotherapy, Chonnam National University Hwasun Hospital, Chonnam, Republic of \\ Korea \\ ${ }^{3}$ Department of Internal Medicine, Chonnam National University Medical School, Gwangju, Republic of Korea \\ ${ }^{4}$ Department of Hematology-Oncology, Chonnam National University Hwasun Hospital, Chonnam, Republic of Korea \\ ${ }^{5}$ Department of Neurosurgery, Chonnam National University Hwasun Hospital \& Medical School, Gwangju, Republic of Korea \\ Correspondence to: Tae-Young Jung, email: jung-ty@chonnam.ac.kr \\ Keywords: multipeptide, immunotherapy, glioblastoma, dendritic cell \\ Received: October 01,2015 Accepted: June 29,2016 Published: July 08, 2016
}

\section{ABSTRACT}

We investigated the use of cytotoxic T-lymphocyte (CTL) epitopes in peptide immunotherapy for glioblastoma. Three peptides (ERBB2, BIRC5 and CD99) were selected based on their peptide-T2 cell binding affinities and combined in a multipeptide cocktail or a branched multipeptide synthesized with mini-polyethylene glycol spacers. Dendritic cells (DCs) pulsed with the multipeptide cocktail or branched multipeptide were compared based on their immunophenotype and cytokine secretion. FACS analysis of alpha-type 1 polarized dendritic cells (aDC1s) revealed that both groups highly expressed CD80, CD83 and CD86, indicating that both treatments efficiently generated mature aDC1s with the expected phenotype. Production of IL12p70, IL-12p40 and IL-10 also increased upon aDC1 maturation in both groups. CTLS stimulated by either aDC1 group ("DC-CTLs") included numerous IFN- $\gamma-$-secreting cells against $\mathrm{T} 2$ cells loaded with the corresponding multipeptides. Large numbers of IFNy-secreting cells were observed when human glioblastoma cell lines and primary cells were treated with multipeptide-pulsed DC-CTLs. Both multipeptide-pulsed DC-CTL groups exhibited cytotoxic activity of $40-60 \%$ against the U251 cell line and $60-80 \%$ against primary cells. Branched multipeptide from ERBB2, BIRC5 and CD99 stably bound with $T 2$ cells, and its cytotoxicity toward target cells was similar to that of the multipeptide cocktail. Thus, branched multipeptides could be promising candidates for immunotherapeutic glioblastoma treatment.

\section{INTRODUCTION}

Gliomas are the most common primary tumors of the central nervous system [1,2]. Despite advances in conventional treatments such as surgical resection, radiation therapy and chemotherapy, the prognosis for most patients with glioblastomas is poor. Even with intensive treatment, glioblastomas frequently recur due to continued growth of the residual microscopic disease located beyond surgical resection margins [3].
In recent years, numerous attempts have been made to develop immunotherapies and adjuvant therapies to more effectively treat glioblastomas [3-6]. One promising modality for glioblastoma treatment is specific immunotherapy using dendritic cells (DCs) $[4,7]$. This modality requires information about the target antigens and their epitope peptides that are recognized by $\mathrm{T}$ cells. A major challenge for in vitro induction of glioblastoma-reactive cytotoxic T-lymphocytes (CTLs) for adoptive immunotherapy is the identification of major histocompatibility complex (MHC) 
class I-restricted CTL epitopes derived from glioblastoma tumor-associated antigens (TAAs). DCs are potent antigenpresenting cells (APCs), which are highly efficient in antigen presentation and the stimulation of $\mathrm{T}$ lymphocytes [8]. However, DC immunotherapy has some disadvantages, such as the limited availability of materials for designing vaccines, the costly and labor-intensive preparation, and the requirement of a reliable laboratory marker. This situation has stimulated interest in exploring the usefulness of peptide immunotherapy for patients with malignant glioblastomas [6, 9-11]. The advantages of synthetic CTL epitope peptides include their ease of production, pathogen-free nature and chemical stability.

Previous studies have discussed brain TAAs and their peptides, but as human brain tumors express a wide variety of TAAs, there is still a need to identify therapeutically useful glioblastoma-TAAs and their epitope peptides [12-16]. In our previous study, we detected positive expression of v-erb-b2 erythroblastic leukemia viral oncogene homolog-2 (ERBB2), baculoviral IAP repeat containing-5 (BIRC5) and the glycoprotein CD99 in most glioblastoma tissues, and negative expression in normal brain tissues [17]. As these TAAs are highly expressed in glioblastoma tissues and cell lines, they could be the targets of synthetic multipeptide immunotherapy.

Synthetic CTL epitope peptides such as multipeptides have greater molecular weights and immunogenicity than their corresponding peptides [10, 18]. In this study, we designed a branched multipeptide by using mini-polyethylene glycol (mini-PEG) spacers. The attachment of mini-PEGs to peptides increases their metabolic half-lives, lowers their non-specific binding and shields them from proteolytic enzymes [19]. Multipeptides can induce human leukocyte antigen (HLA)-restricted and tumor-reactive CTLs. HLA-A*0201 is highly frequent in the populations of Northern Asia and North America, and is the most common type of HLA in Korea (16.5\%) [20].

We selected three peptides derived from the brain TAAs of ERBB2, BIRC5 and CD99 with an HLA-A*0201-binding epitopes recognized by CTLs, investigated the potential of peptide immunotherapy for glioblastoma by using CTLs generated by branched multipeptide-pulsed alpha-type 1 polarized dendritic cells $(\alpha \mathrm{DC} 1 \mathrm{~s})$, and compared this immunotherapy with a multipeptide cocktail of ERBB2, BIRC5 and CD99.

\section{RESULTS}

\section{Selection and synthesis of ERBB2, BIRC5 and CD99 peptides}

We measured the binding affinity of HLA-A*0201specific peptides in a peptide-T2 binding assay, and selected peptides $(20 \mu \mathrm{g} / \mathrm{mL}$ each) with high scores for further analysis: ERBB2 ${ }_{369}$ (KIFGSLAFL), BIRC5 (LMLGEFLKL) and CD99 (LLLFGLLGV) (Figure 1).
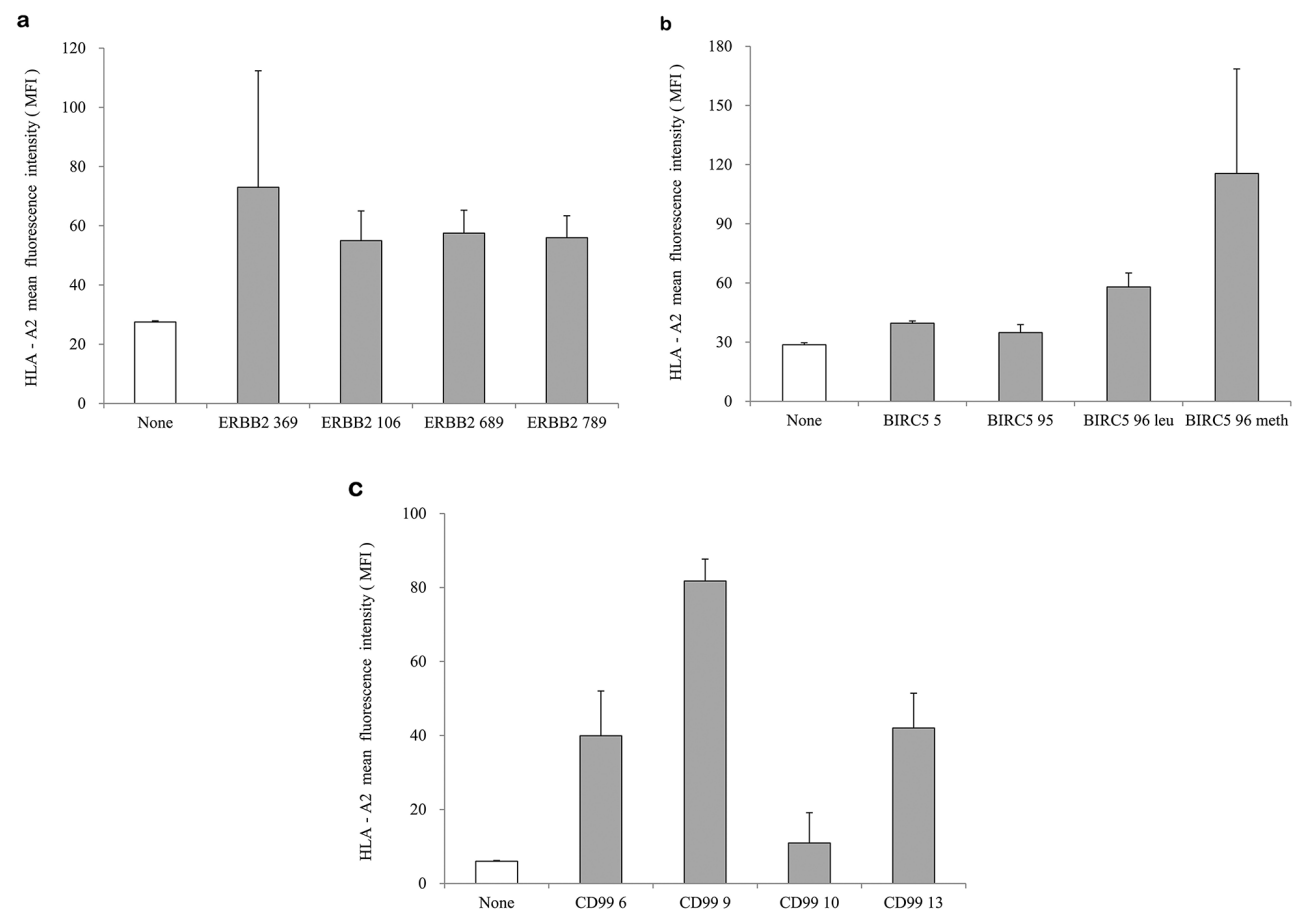

Figure 1: Peptide-binding affinity and selection of peptide candidates. a. ERBB2 peptides, b. BIRC5 peptides, c. CD99 peptides. ERBB2 ${ }_{369}$ (KIFGSLAFL), BIRC5 ${ }_{96 \text { methionine }}$ (LMLGEFLKL) and CD99 (LLLFGLLGV) were selected as HLA-A*0201-specific peptides with high scores in the peptide-T2 binding assay. The concentration of each peptide was $20 \mu \mathrm{g} / \mathrm{mL}$. The values represent the mean $\mathrm{MFI} \pm \mathrm{SE}$ of three separate experiments. 
Furthermore, we used mini-PEG spacers to create their corresponding branched multipeptide, which was designated as (ERBB2 - mini PEG2 - K \{BIRC5 - mini PEG2 - K [CD99 - mini PEG2]\}) [21].

\section{HLA-A02 binding affinity and stability of the multipeptide cocktail and branched multipeptide}

The T2 cell line was used to evaluate the binding affinity of the HLA-A*0201-specific multipeptide cocktail and the branched multipeptide. In the peptide-binding assay, the multipeptide cocktail dose-dependently increased the HLA-A02 mean fluorescence intensity (MFI) in T2 cells $(0,7.5,15.0,22.5,30.0 \mu \mathrm{g} / \mathrm{mL})$ (Figure 2a). However, in cells treated with the branched multipeptide, the mean MFI increased until the total peptide concentration reached $22.5 \mu \mathrm{g} / \mathrm{mL}(7.5 \mu \mathrm{g} / \mathrm{mL} /$ peptide) and decreased thereafter. Therefore, $22.5 \mu \mathrm{g} /$ $\mathrm{mL}$ was selected as the optimal peptide concentration for evaluating HLA-A02 binding stability. Flow cytometric analysis revealed a difference in the peptide-binding stabilities of the multipeptide cocktail and the branched

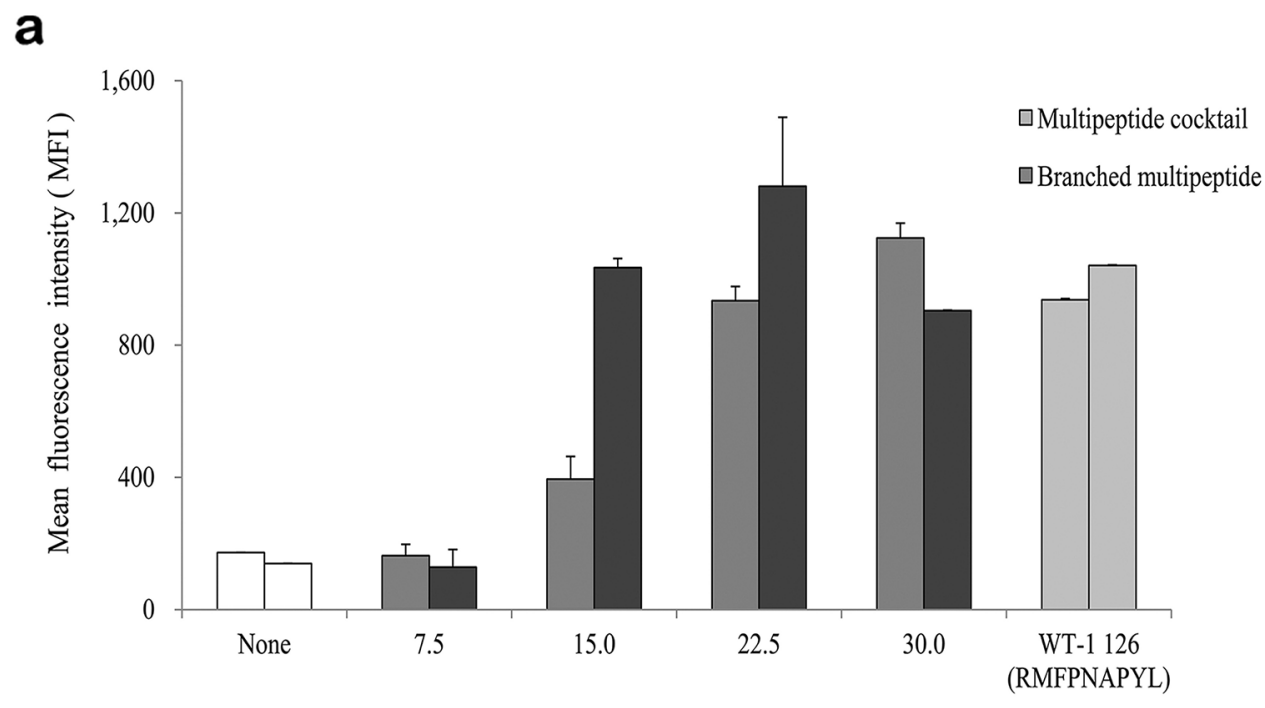

Multipeptide concentration $(\mu \mathrm{g} / \mathrm{mL})$

b

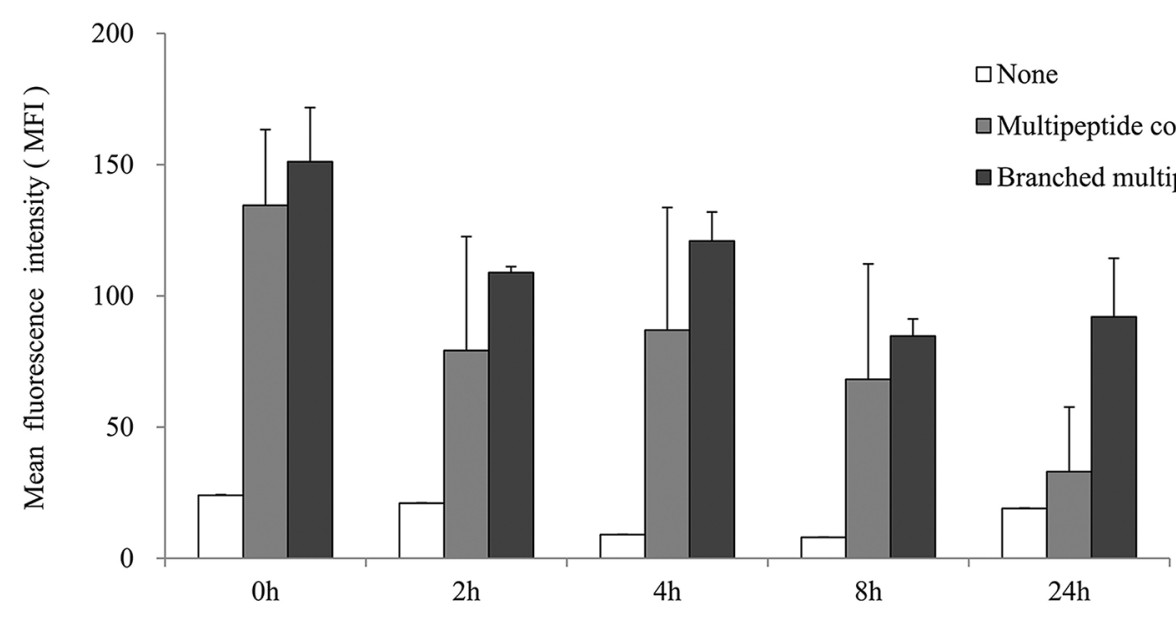

Time post-Brefeldin A treatment ( hours )

Figure 2: HLA-A02 binding affinity and stability of the multipeptide cocktail and branched multipeptide. a. Binding affinity: The multipeptide cocktail dose-dependently increased the HLA-A02 mean MFI in T2 cells. In cells treated with the branched multipeptide, the mean MFI increased until the total peptide concentration reached $22.5 \mu \mathrm{g} / \mathrm{mL}(7.5 \mu \mathrm{g} / \mathrm{mL} /$ peptide), which was selected as the optimal peptide concentration. b. Binding stability: While the stability of the branched multipeptides was maintained up to 24 hours post-BFA treatment, the stability of the multipeptide cocktail was only maintained up to 8 hours post-BFA treatment. The values represent the mean $\mathrm{MFI} \pm \mathrm{SE}$ of three separate experiments. 
multipeptide. Both multipeptides tended to destabilize over time; however, the stability of the branched multipeptide was maintained for up to 24 hours post-Brefeldin A (BFA) treatment, while the stability of the multipeptide cocktail was only maintained for up to 8 hours post-BFA treatment (Figure 2b). Moreover, at 24 hours post-BFA treatment, we observed a decrease in HLA-A02-specific affinity.

\section{Characterization of $\alpha \mathrm{DC} 1 \mathrm{~s}$ pulsed with the multipeptide cocktail or the branched multipeptide}

We used flow cytometric analysis to determine the phenotypes of $\alpha \mathrm{DC} 1 \mathrm{~s}$ pulsed with the multipeptide cocktail or the branched multipeptide, as well as that of unpulsed cells. ERBB2, BIRC5 and CD99 individual peptide-pulsed $\alpha \mathrm{DC} 1 \mathrm{~s}$ were termed as "A,B,C-pulsed $\alpha \mathrm{DC} 1 \mathrm{~s}$," while mixed ERBB2, BIRC5 and CD99 peptide-pulsed $\alpha$ DC1s were termed as "A/B/C-pulsed $\alpha \mathrm{DC} 1 \mathrm{~s}$," and branched multipeptide-pulsed $\alpha \mathrm{DC} 1 \mathrm{~s}$ were termed as "Branched multipeptide-pulsed $\alpha \mathrm{DC} 1 \mathrm{~s}$ " (A: ERBB2, B: BIRC5, C: CD99). As shown in Figure 3, the above-mentioned four $\alpha \mathrm{DC} 1$ populations (Unpulsed, A,B,C-pulsed, A/B/C-pulsed,
Branched multipeptide-pulsed) displayed a characteristic set of mature $\alpha \mathrm{DC} 1$ surface markers not displayed by immature DCs. No significant differences were found in the expression of CD80, CD83, CD86, or CCR7 among the four $\alpha \mathrm{DC} 1$ populations. Thus, $\alpha \mathrm{DC} 1 \mathrm{~s}$ pulsed with the multipeptide cocktail or branched multipeptide efficiently generated mature $\alpha \mathrm{DC} 1 \mathrm{~s}$ with the expected phenotype.

We then measured IL-12p40, IL-12p70, IL-10 and IL-23 production by unpulsed $\alpha \mathrm{DC} 1 \mathrm{~s}$ and mature $\alpha \mathrm{DC} 1 \mathrm{~s}$ pulsed with the multipeptide cocktail or the branched multipeptide (Figure 4). Mature $\alpha \mathrm{DC} 1 \mathrm{~s}$ produced higher levels of IL-12p40 and IL-12p70 than immature DCs. After subsequent stimulation with CD40L-transfected J558 cells, the mature $\alpha \mathrm{DC} 1 \mathrm{~s}$ pulsed with the multipeptide cocktail or the branched multipeptide and unpulsed $\alpha \mathrm{DC} 1 \mathrm{~s}$ produced similar levels of IL-12p40 and IL-12p70. Similarly, the production of the inhibitory cytokine IL10 by mature $\alpha \mathrm{DC} 1 \mathrm{~s}$ increased after CD40L stimulation. The production of IL-12p40, IL-12p70 and IL-10 did not differ significantly among unpulsed $\alpha \mathrm{DC} 1 \mathrm{~s}, \alpha \mathrm{DC} 1 \mathrm{~s}$ pulsed with the multipeptide cocktail and those pulsed with branched multipeptide ( $p=0.322,0.827$ and 0.099 , respectively). IL-23 production by $\alpha \mathrm{DC} 1 \mathrm{~s}$ did not increase
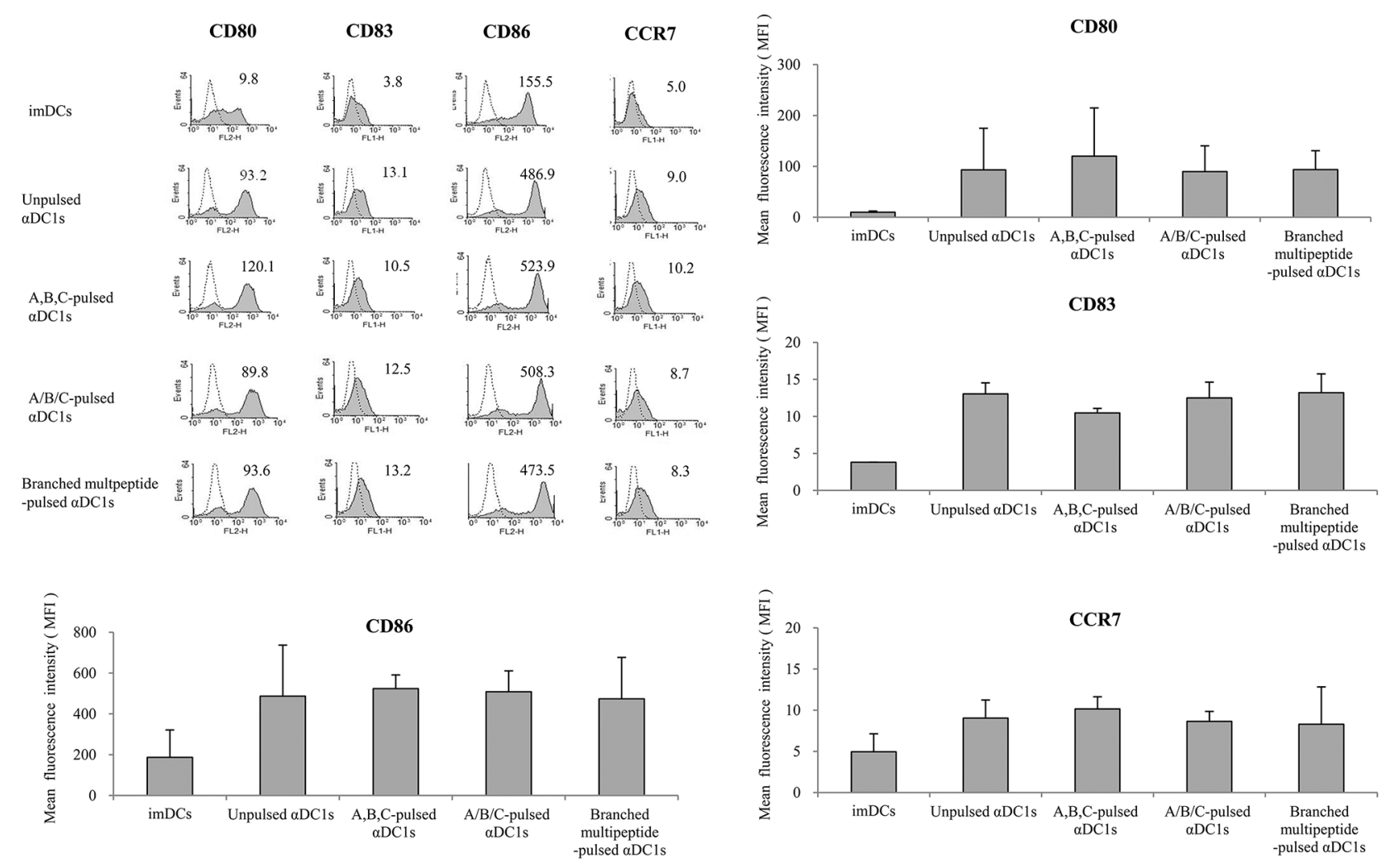

Figure 3: Immunophenotype of DCs pulsed with multipeptides for the cell surface markers (CD80, CD83, CD86, CCR7). No significant differences were found in the expression of CD80, CD83, CD86, or CCR7 (relative to that of immature DCs) between the four $\alpha \mathrm{DC} 1$ populations (Unpulsed, A,B,C-pulsed, A/B/C-pulsed, Branched multipeptide-pulsed). Results are reported as mean MFI values \pm SE of three separate experiments. (imDCs: immature DCs; Unpulsed $\alpha$ DC1s: peptide-unpulsed $\alpha$ DC1s; A,B,C-pulsed $\alpha \mathrm{DC} 1 \mathrm{~s}$ : ERBB2, BIRC5 and CD99 individual peptide-pulsed $\alpha \mathrm{DC} 1 \mathrm{~s} ; \mathrm{A} / \mathrm{B} / \mathrm{C}-$ pulsed $\alpha \mathrm{DC} 1 \mathrm{~s}$ : mixed ERBB2, BIRC5 and CD99 peptidepulsed $\alpha \mathrm{DC1}$ s; Branched multipeptide-pulsed $\alpha \mathrm{DC} 1 \mathrm{~s}$ : branched multipeptide-pulsed $\alpha \mathrm{DC} 1 \mathrm{~s})$. 
significantly during the maturation phase. After subsequent stimulation with CD40L-transfected J558 cells, branched multipeptide-pulsed mature $\alpha \mathrm{DC} 1 \mathrm{~s}$ produced greater levels of IL-23 than unpulsed and multipeptide cocktailpulsed $\alpha \mathrm{DC} 1 \mathrm{~s}$. The difference in IL-23 production was statistically significant $(p=0.047)$.

\section{IFN- $\gamma$ secretion by multipeptide cocktail- and branched multipeptide-specific CTLs against multipeptide-pulsed $\mathrm{T} 2$ cells}

Multipeptide cocktail-pulsed T2 cells (A,B,C $\mathrm{T} 2, \mathrm{~A} / \mathrm{B} / \mathrm{C} \mathrm{T} 2$ ), branched multipeptide-pulsed T2 cells (Branched T2), unpulsed T2 cells (Unpulsed T2), and HIV peptide-pulsed T2 cells (HIV T2) were used as target cells. Three effector CTL groups (A,B,C DCCTLs, A/B/C DC-CTLs and Branched DC-CTLs) were compared for their ability to recognize T2 cells pulsed with the multipeptide cocktail or branched multipeptide. As shown in Figure 5, the CTLs generated by $\alpha \mathrm{DC} 1 \mathrm{~s}$

$$
\text { IL-12p40 }
$$

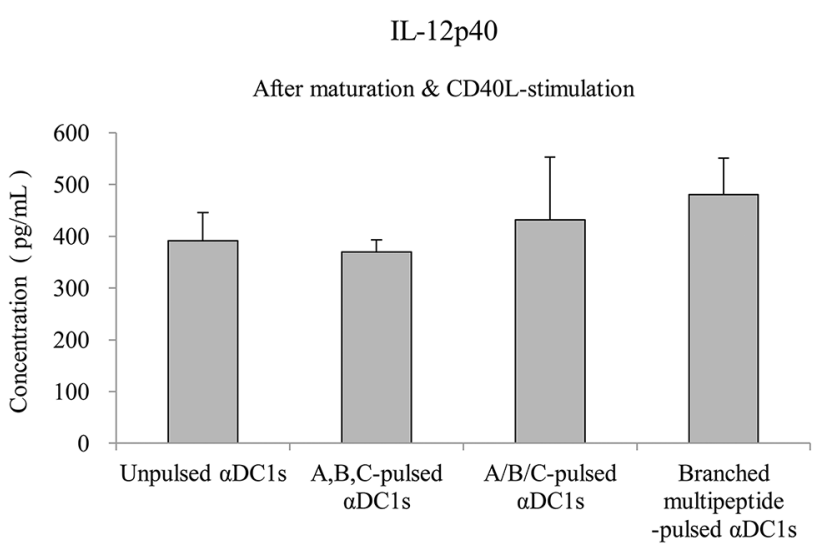

IL-10

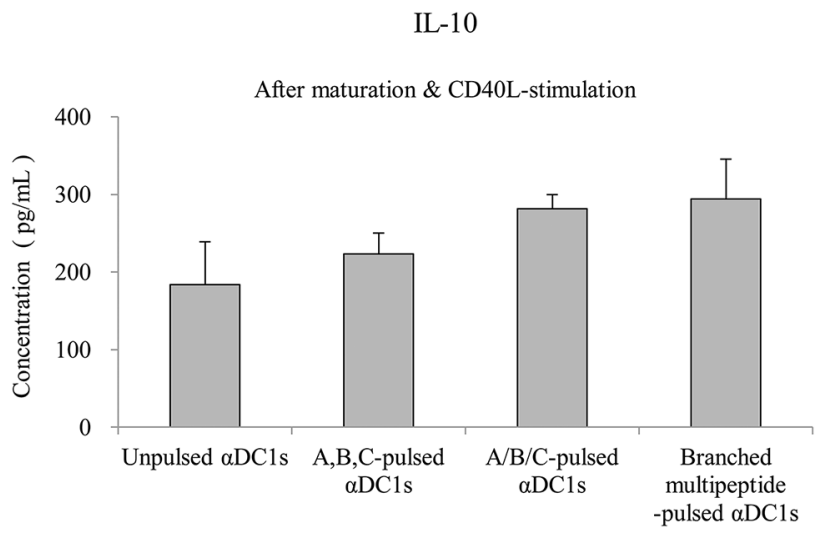

pulsed with the multipeptide cocktail or branched multipeptide included a large number of IFN- $\gamma$-secreting cells, and were more potent than the CTLs stimulated by unpulsed $\alpha \mathrm{DC} 1 \mathrm{~s}$ at an effector/target $(\mathrm{E} / \mathrm{T})$ ratio of 10:1. A,B,C DC-CTLs, A/B/C DC-CTLs and Branched DC-CTLs more specifically produced IFN- $\gamma$ against the A,B,C T2, A/B/C T2 and Branched T2 target cells, respectively. The specificity of the CTLs was statistically significant ( $p=0.002,0.011$ and 0.022 , respectively).

\section{IFN- $\gamma$ secretion by multipeptide cocktail- and branched multipeptide-specific CTLs against human glioblastoma cell lines and primary glioblastoma cells}

We used HLA-A2-positive human glioblastoma cell lines and primary cells for additional experiments. Western blotting revealed that the U87 and U251 cell lines and primary cells positively expressed ERBB2, BIRC5 and CD99 (Figure 6). The U343 cell line positively expressed

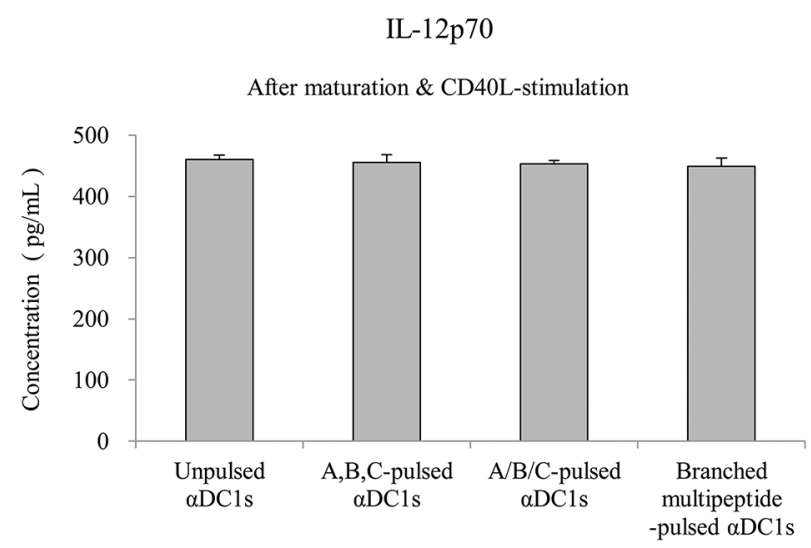

IL-23

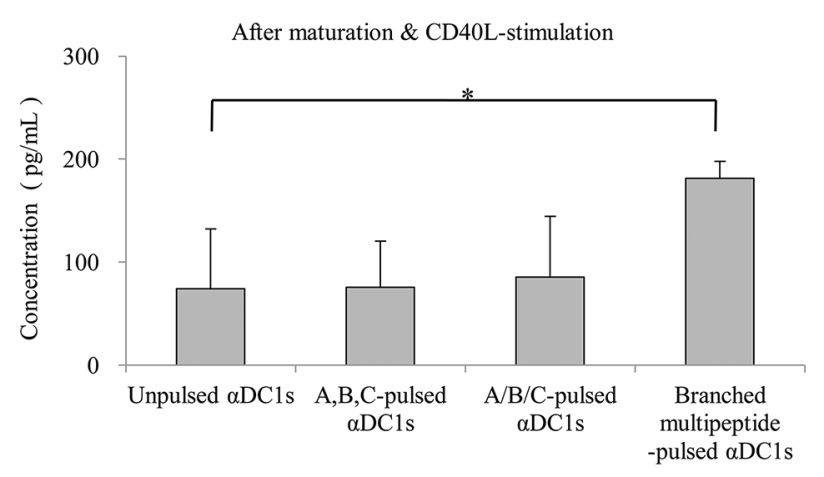

Figure 4: Cytokine secretion of $\alpha$ DC1s pulsed with multipeptides. Production of IL-12p40, IL-12p70, IL-10 and IL-23. Cytokines secreted into the culture supernatants were measured by ELISA after stimulation with CD40 ligand-transfected J558 cells. The production of IL-12p40, IL-12p70, and IL-10 did not differ significantly among unpulsed $\alpha \mathrm{DC} 1 \mathrm{~s}, \alpha \mathrm{DC} 1 \mathrm{~s}$ pulsed with the multipeptide cocktail and those pulsed with branched multipeptide. Branched multipeptide-pulsed mature $\alpha$ DC1s produced higher levels of IL-23 than unpulsed and multipeptide cocktail-pulsed $\alpha \mathrm{DC} 1 \mathrm{~s}(p=0.047)$. The results shown are from the triplicate culture from three independent experiments and are expressed as the mean \pm SE. (Unpulsed $\alpha$ DC1s: peptide-unpulsed $\alpha$ DC1s; A,B,C-pulsed $\alpha$ DC1s: ERBB2, BIRC5 and CD99 individual peptide-pulsed $\alpha \mathrm{DC} 1 \mathrm{~s} ; \mathrm{A} / \mathrm{B} / \mathrm{C}$-pulsed $\alpha \mathrm{DC} 1 \mathrm{~s}$ : mixed ERBB2, BIRC5 and CD99 peptide-pulsed $\alpha \mathrm{DC} 1 \mathrm{~s}$; Branched-multipeptide-pulsed $\alpha \mathrm{DC} 1 \mathrm{~s}$ : branched-multipeptide-pulsed $\alpha \mathrm{DC} 1 \mathrm{~s})(*: \mathrm{p}<0.05)$. 


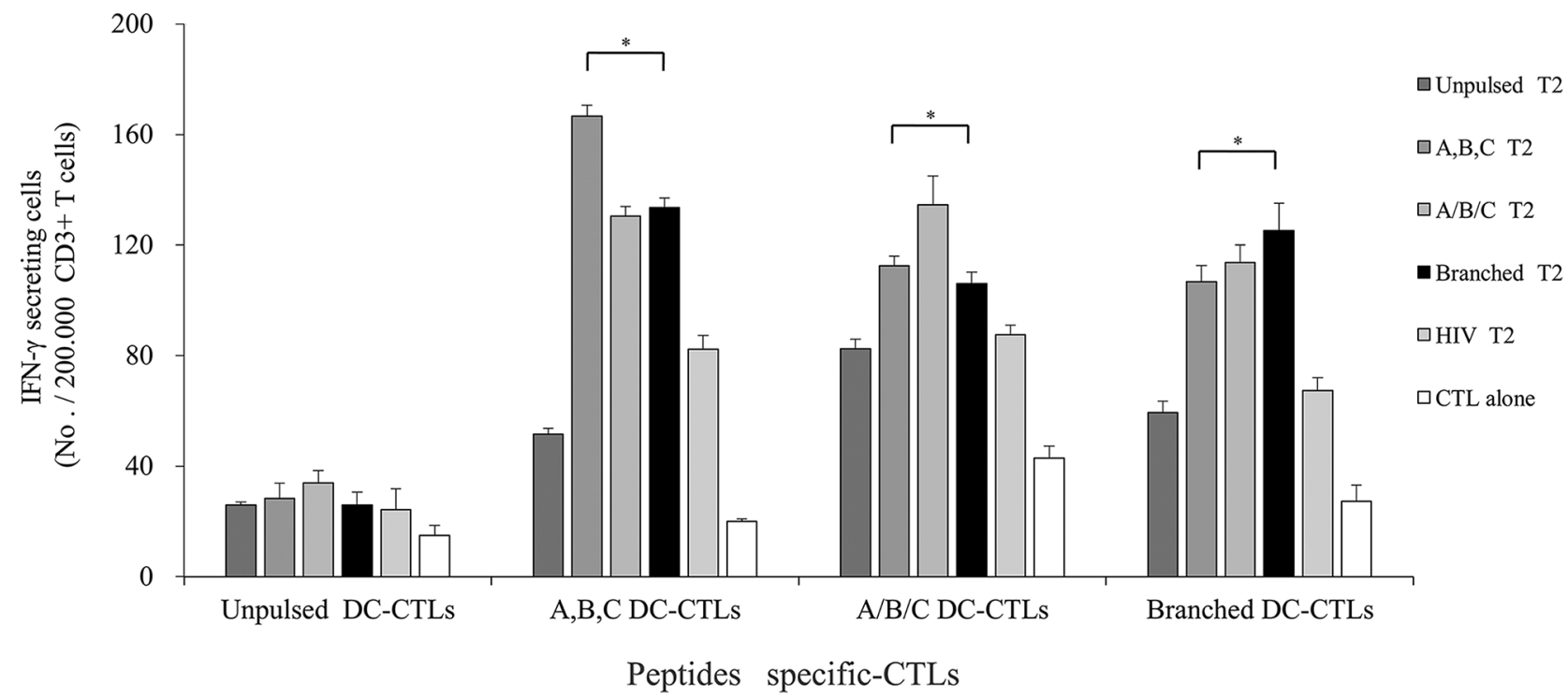

Figure 5: IFN- $\gamma$ ELISPOT assay of multipeptide-specific CTLs against multipeptide-pulsed T2 cells. IFN- $\gamma$ secretion of A,B,C DC-CTLs, A/B/C DC-CTLs and Branched DC-CTLs. Multipeptide-pulsed T2 cells were used as the target cells, and unpulsed and HIV peptide-pulsed T2 cells were used as negative controls. The E/T ratio was 10:1. A,B,C DC-CTLs, A/B/C DC-CTLs and Branched DC-CTLs more specifically produced IFN- $\gamma$ against the A,B,C T2, A/B/C T2 and Branched T2 target cells, respectively. The specificity of the CTLs was statistically significant ( $p=0.002,0.011$ and 0.022 , respectively). (A,B,C DC-CTLs: ERBB2, BIRC5 and CD99 individual peptide-pulsed DCs stimulated with $\mathrm{CD}^{+}$T cells; A/B/C DC-CTLs: mixed ERBB2, BIRC5 and CD99 peptide-pulsed DCs stimulated with $\mathrm{CD}^{+} \mathrm{T}$ cells; Branched DC-CTLs: branched-multipeptide-pulsed DCs stimulated with $\mathrm{CD}^{+} \mathrm{T}$ cells; Unpulsed T2: peptide-unpulsed T2 cells; A,B,C T2: T2 cells individually pulsed with the ERBB2, BIRC5 and CD99 peptides; A/B/C T2: T2 cells pulsed with mixed ERBB2, BIRC5 and CD99 peptides; Branched T2: branched multipeptide-pulsed T2 cells; HIV T2: HIV peptide-pulsed T2 cells) (*: p < 0.05).

$1 \quad 2 \quad 3 \quad 4$

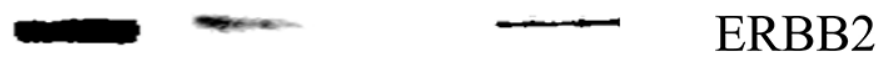

BIRC5

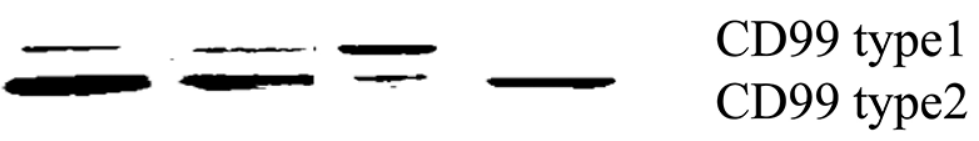

ACTB

Figure 6: BIRC5, CD99 and ERBB2 expression of human glioblastoma cell lines and primary glioblastoma cells by Western blot. All cells were HLA-A2 positive. The U87 and U251 cell lines and primary cells positively expressed ERBB2, BIRC5 and CD99. The U343 cell line positively expressed BIRC5 and CD99. (Lane 1: U87 cell line, Lane 2: U251 cell line, Lane 3: U343 cell line, Lane 4: Primary glioblastoma cells). 
BIRC5 and CD99. IFN- $\gamma$ secretion against glioblastoma cell lines and primary glioblastoma cells was studied at an E/T ratio of 10:1 (Figure 7). This experiment was performed with multipeptide cocktail-specific CTLs (A,B,C DC-CTLs) and branched multipeptide-specific CTLs (Branched DC-CTLs), with the U87, U251 and U343 cell lines and primary glioblastoma cells as the target cells. Unpulsed DC-CTLs were used as the negative control. A,B,C DC-CTLs and Branched DC-CTLs produced a higher number of IFN- $\gamma$ spots than Unpulsed DC-CTLs against glioblastoma cell lines and primary glioblastoma cells. A,B,C DC-CTLs and Branched DCCTLs exhibited a specific response, and clearly differed from Unpulsed DC-CTLs in their ability to produce IFN- $\gamma$ against the target cells.

\section{Lactate dehydrogenase release induced by multipeptide cocktail- and branched multipeptide-specific CTLs in the U251 glioblastoma cell line and primary glioblastoma cells}

We tested the ability of multipeptide cocktail- and branched multipeptide-specific CTLs to kill U251 and primary cells by using a standard LDH release assay at an $\mathrm{E} / \mathrm{T}$ ratio of $10: 1$. For the $\mathrm{U} 251$ cell line, A,B DCCTLs, B,C DC-CTLs, A,B,C DC-CTLs and Branched
DC-CTLs exhibited cytotoxic activities of 40-60\% (Figure 8a). For primary cells, A,B DC-CTLs, A,B,C DC-CTLs and Branched DC-CTLs exhibited cytotoxic activities of $60-80 \%$ (Figure $8 \mathrm{~b}$ ). Incubation with an MHC class I antibody reduced cytotoxic activity to approximately $20 \%$ cell lysis in both the U251 cell line and primary cells, confirming that the cytotoxicity was MHC class I-specific.

\section{DISCUSSION}

A broad range of immunological defects have been documented for glioblastoma patients, including reduced $\mathrm{T}$ cell numbers, impaired $\mathrm{T}$ cell responsiveness, and defective signaling after $\mathrm{T}$ cell receptor (TCR)/ CD3 stimulation [22]. Even with these limitations, DC-based brain tumor immunotherapy has been reported to be successful in animal models as well as in humans, and DC vaccination has been found to be safe and not associated with autoimmunity [7, 23, 24]. Several vaccines composed of peptide-pulsed DCs have been designed based on prior identification of CTL-defined synthetic peptide epitopes. However, DC immunotherapy has some disadvantages, such as the limited availability of materials for designing vaccines, the labor-intensive preparation, and the requirement of a reliable laboratory marker.

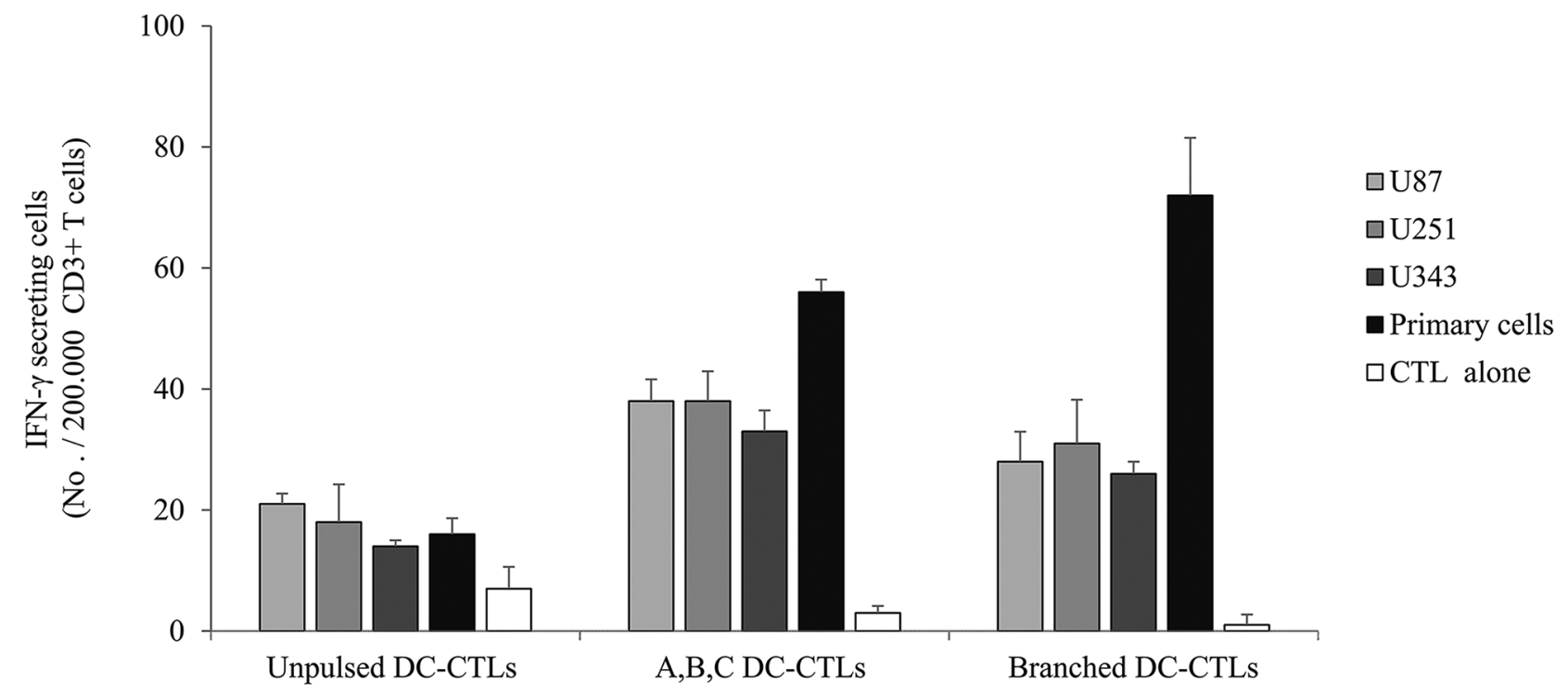

Peptides specific-CTLs

Figure 7: IFN- $\gamma$ ELISPOT assay of multipeptide-specific CTLs against glioblastoma cell lines and primary glioblastoma cells. IFN- $\gamma$ secretion of A,B,C DC-CTLs and Branched DC-CTLs. A,B,C DC-CTLs and Branched DC-CTLs produced a higher number of IFN- $\gamma$ spots against glioblastoma cell lines and primary glioblastoma cells than Unpulsed DC-CTLs. A,B,C DC-CTLs and Branched DC-CTLs exhibited a specific response, and clearly differed from Unpulsed DC-CTLs in their ability to produce IFN- $\gamma$ against the target cells. (Unpulsed DC-CTLs: peptide-unpulsed DCs stimulated with autologous CD3 ${ }^{+}$T cells; A,B,C DC-CTLs: ERBB2, BIRC5 and CD99 individual peptide-pulsed DCs stimulated with $\mathrm{CD}^{+} \mathrm{T}$ cells; Branched DC-CTLs: branched-multipeptide-pulsed DCs stimulated with $\mathrm{CD}^{+}$T cells; U87: U87 glioblastoma cell line; U251: U251 glioblastoma cell line; U343: U343 glioblastoma cell line; Primary cells: primary glioblastoma cells; CTL alone: no target cells). 
A recent study demonstrated the clinical benefit of peptide immunotherapy $[6,25]$. The peptide vaccine was affordable, easy to manufacture, and customizable to individual patients' antigen profiles. Synthetic long peptides resist protease activity, prolong presentation to APCs, enhance immunogenicity, and induce

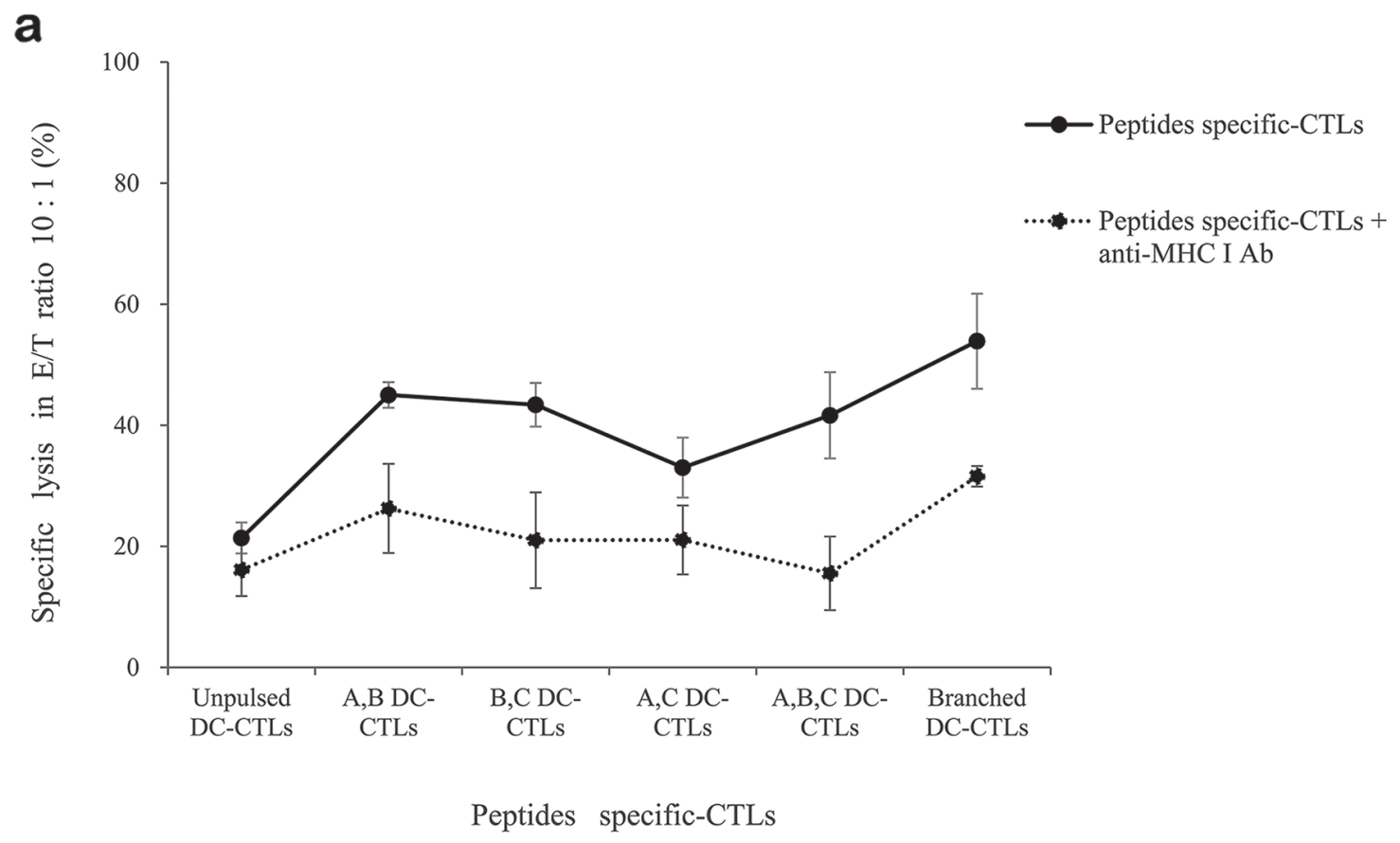

b

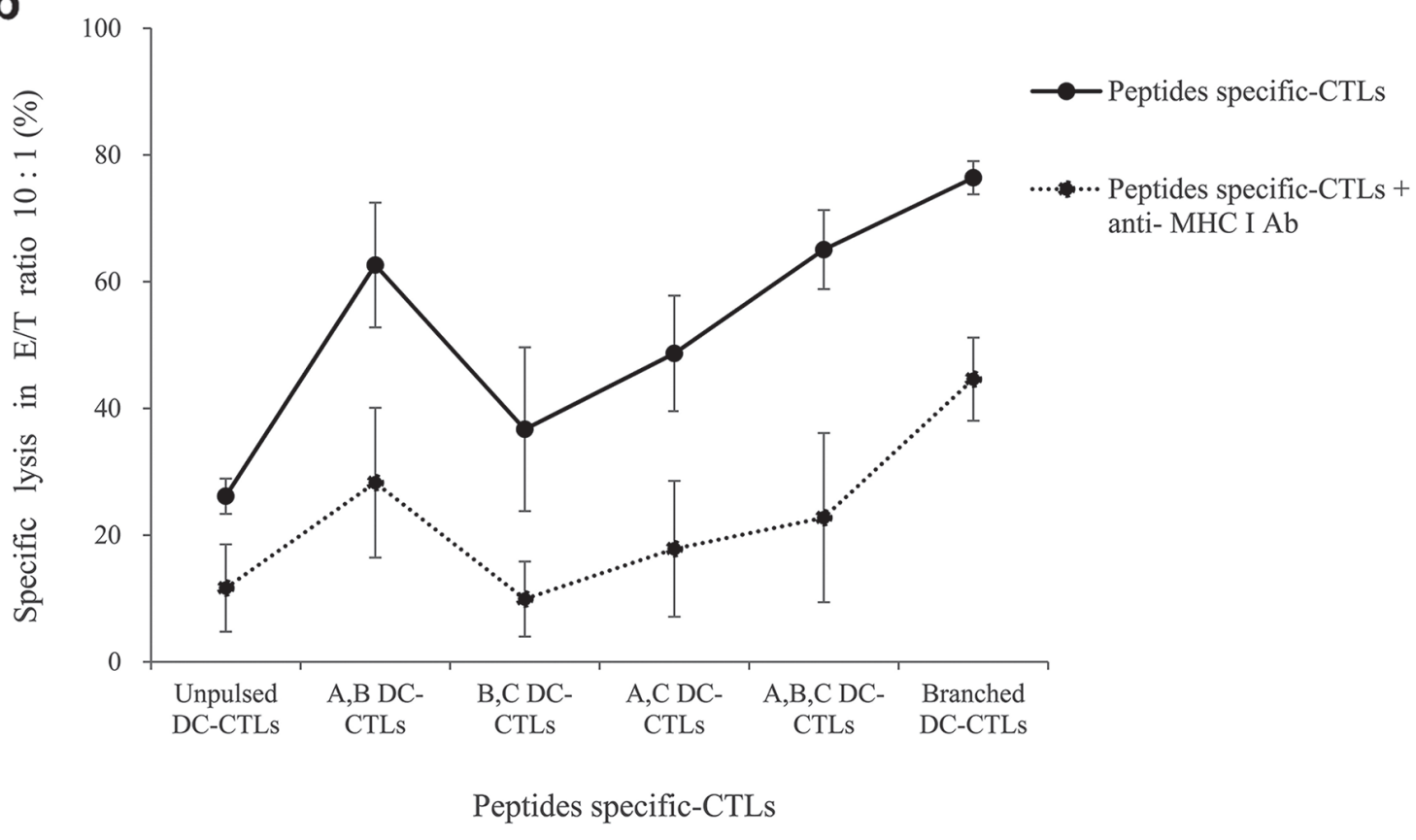

Figure 8: Lactate dehydrogenase release induced by multipeptide cocktail- and branched multipeptide-specific CTLs in the $\mathbf{U} 251$ glioblastoma cell line and primary glioblastoma cells. LDH release by the U251 cell line a. and primary glioblastoma cells b. For the U251 cell line, A,B DC-CTLs, B,C DC-CTLs, A,B,C DC-CTLs and Branched DC-CTLs exhibited cytotoxic activity of 40$60 \%$. For primary cells, A,B DC-CTLs, A,B,C DC-CTLs and Branched DC-CTLs exhibited cytotoxic activity of 60-80\%. Incubation with an MHC class I antibody reduced the cytotoxic activity to approximately $20 \%$ cell lysis in both types of cells. (A: ERBB2, B: BIRC5, C: CD99. A,B DC-CTLs: ERBB2 and BIRC5 individual peptide-pulsed DCs stimulated with CD3 ${ }^{+}$T cells; B,C DC-CTLs: BIRC5 and CD99 individual peptide-pulsed DCs stimulated with $\mathrm{CD}^{+}$T cells; A,C DC-CTLs: ERBB2 and CD99 individual peptide-pulsed DCs stimulated with $\mathrm{CD}^{+}$T cells; A,B,C DC-CTLs: ERBB2, BIRC5 and CD99 individual peptide-pulsed DCs stimulated with $\mathrm{CD}^{+} \mathrm{T}^{+}$cells; Branched DC-CTLs: branched-multipeptide-pulsed DCs stimulated with $\mathrm{CD}^{+} \mathrm{T}$ cells). 
both T-cytotoxic and T-helper responses. Synthetic multipeptides have greater molecular weights and immunogenicity than their corresponding peptides [18]. In the present study, we designed a peptide immunotherapy for glioblastoma using ERBB2, BIRC5 and CD99 peptides as TAAs [17]. Previous studies have indicated that BIRC5 and ERBB2 protein expression is absent from the normal brain, while CD99 expression is relatively low (www. proteinatlas.org) [26]. Among other normal tissues, the oral mucosa, esophagus, genital organs and skin express medium levels of the BIRC5 protein. ERBB2 expression is medium in the appendix, heart muscle, skeletal muscle, nasopharynx, bronchus, bladder, breast, female genitalia and skin. CD99 expression is high in the bone marrow, spleen, nasopharynx, pancreas, esophagus and genital organs, so treatments targeting this protein might have more side effects than those targeting the previous two.

TAA peptides, along with the MHC class I complex, bind to TAA-specific TCRs on $\mathrm{CD}^{+}$cells and activate the $\mathrm{T}$ cells. Thus, epitopes that are correctly presented by tumor cells and are recognized by specific $T$ cells can elicit potent anti-tumor responses. As mentioned above, the branched multipeptide in this study was synthesized with mini-PEG spacers. The attachment of mini-PEGs to peptides increases their metabolic half-lives, lowers their non-specific binding and shields them from proteolytic enzymes and pharmacokinetics [21]. On the other hand, mini-PEGs may interfere with receptor binding [21].

A major challenge in the induction of antigenspecific CTLs is the identification of MHC class I-restricted CTL epitopes derived from glioblastoma TAAs [12, 15]. Identification of CTL epitopes from these antigens is a critical step in the development of peptide immunotherapies for cancer. In the present study, we investigated the possibility of using peptide immunotherapy for glioblastoma by using ERBB2, BIRC5- and CD99-specific CTLs generated by multipeptide-pulsed DCs. We identified and synthesized ERBB2, BIRC5 and CD99 peptides as well as their corresponding branched multipeptide, and then generated CTLs by using DCs pulsed with these peptides as APCs. These CTLs specifically recognized ERBB2, BIRC5 and CD99 multipeptide-pulsed T2 cells and were able to lyse target T2 cells positive for ERBB2, BIRC5 and CD99 efficiently. However, T2 cells can present an unnaturally high number of epitopes upon exposure to a high peptide concentration, so their use may lead to an inaccurate assessment of T-cell sensitivity for immunotherapeutic applications [27]. Therefore, glioblastoma cell lines and primary glioblastoma cells were also used as target cells. As shown in Figure 7, CTLs stimulated by ERBB2, BIRC5 and CD99 peptide-pulsed DCs could recognize these three peptides and produce IFN- $\gamma$ when the peptides were naturally presented by glioblastoma cell lines and primary glioblastoma cells in the context of HLA-A*0201, and could kill ERBB2-, BIRC5- and
CD99-positive tumor cells in the LDH cytotoxicity assay. CTLs stimulated with branched multipeptidepulsed DCs exhibited comparable cytotoxicity to those stimulated with different combinations of the three peptide-pulsed DCs.

In summary, we have described a branched multipeptide vaccine capable of stimulating a response to multiple $\mathrm{CD}^{+} \mathrm{T}$ cell epitopes from glioblastoma-TAAs such as ERBB2, BIRC5 and CD99. Finally, through this work, we confirmed that the branched multipeptide of ERBB2, BIRC5 and CD99 stably bound to T2 cells and was similar to the multipeptide cocktail in its cytotoxicity. Branched multipeptide therapy can thus be considered a useful immunotherapeutic modality for glioblastoma.

\section{MATERIALS AND METHODS}

\section{Target cells}

The T2 cell line, a human $\mathrm{B}$ and $\mathrm{T}$ cell hybrid expressing HLA-A2 molecules, was obtained from the Korean Cell Line Bank, Seoul, Korea. T2 cells were cultured in RPMI-1640 supplemented with 10\% fetal bovine serum (FBS) and 1\% penicillin-streptomycin (PS) (all from Gibco-BRL, Grand Island, NY, USA).

The human glioblastoma cell lines U87, U251 and U343 were obtained from the Korean Cell Line Bank (Seoul, Korea) and the Brain Tumor Research Center, University of California (San Francisco, CA, USA). Brain tissue specimens were obtained from patients undergoing surgery in the Department of Neurosurgery at Chonnam National University Hwasun Hospital. The fresh tumor samples were washed, fractionated in PBS, and enzymatically dissociated with $0.3 \%$ collagenase. The primary glioblastoma cells were then resuspended. All these cells were HLA-A2-positive. These cells were routinely grown in Dulbecco's Modified Eagle's Medium (DMEM; Gibco-BRL, Gaithersburg, MD, USA) supplemented with $10 \% \mathrm{FBS}$ and $1 \%$ PS at $37^{\circ} \mathrm{C}$ in a humidified atmosphere containing 95\% air and 5\% $\mathrm{CO}_{2}$.

\section{ERBB2, BIRC5 and CD99 expression by western blot}

The U87, U251 and U343 cell lines were homogenized with lysis buffer [50 mM Tris ( $\mathrm{pH} 8.0), 5$ $\mathrm{mM}$ EDTA, $150 \mathrm{mM}$ sodium chloride, $0.5 \%$ deoxycholic acid, $0.1 \%$ sodium dodecyl sulfate (SDS), 1\% NP40, $1 \mathrm{mM}$ phenyl methane-sulfonyl fluoride (PMSF) and $1 \mathrm{mg} / \mathrm{mL}$ protease inhibitor cocktail]. Protein concentrations were determined with a Bio-Rad protein assay kit (Bio-Rad, Hercules, CA, USA). Subsequently, $50 \mu \mathrm{g}$ of whole cell lysate was separated by $15 \%$ SDS-polyacrylamide gel electrophoresis (PAGE) and transferred to a polyvinylidene difluoride membrane (Pall 
Corporation, Ann Arbor, MI, USA). The membrane was then incubated for two hours at room temperature in a solution containing TBST [10 mM TrisCl (pH 8.0), 150 $\mathrm{mM} \mathrm{NaCl}$ and $0.05 \%$ Tween 20] supplemented with 5\% non-fat dry milk, and was probed overnight at $4{ }^{\circ} \mathrm{C}$ with antibodies to ERBB2 (Cell Signaling, USA), BIRC5 (SantaCruz Biotechnology, Santa Cruz, CA, USA), or CD99 (AbCam, Cambridge, United Kingdom). The bound antibodies were visualized with goat anti-rabbit (1:40,000; Jackson Immunoresearch, West Grove, PA, USA) or anti-mouse (1:40,000; BD Biosciences) antibodies conjugated with horseradish peroxidase through the use of enhanced chemiluminescence reagents (ECL; Amersham Bioscience). $\beta$-actin (ACTB) was used as the internal control. We used Multi Gauge 3.0 software (LAS-4000) to estimate the expression of ERBB2, BIRC5 and CD99.

\section{Synthetic peptides}

The research software BIMAS and data from the available literature were used to identify HLA-A*0201specific peptides [28-30] (Table 1). Of the candidate HLA-A*0201-specific peptides, peptides were selected and synthesized for evaluation on the basis of high scores that predict HLA-A*0201 binding, as well as the presence of primary and secondary HLA-A*0201 anchor residues. The three selected peptides (BIRC5, CD99 and ERBB2) and their corresponding branched multipeptide were synthesized. All peptides were synthesized at PEPTRON (Daejeon, Korea). Mini-PEG spacers were used to design the branched multipeptide [21]. The purity of each synthetic peptide was confirmed to be $>95 \%$ by reversephase high-performance liquid chromatography and mass spectrometry. Synthetic peptides were dissolved in dimethyl sulfoxide or distilled water, according to the manufacturer's recommendations, and stored at $-20^{\circ} \mathrm{C}$ until use.

\section{Generation of DCs}

Peripheral blood samples were collected from normal healthy donors carrying HLA-A*0201 after they had provided informed consent, according to the protocol approved by the Institutional Ethics Committee at the Chonnam National University Hwasun Hospital (CNUHH-2015-095). Monocytes were generated from peripheral blood mononuclear cells as previously reported [31]. For the generation of immature DCs, the monocytes were cultured in Iscove's Modified Dulbecco's Medium (Gibco-BRL) with 10\% heat-inactivated FBS (Hyclone, Logan, UT, USA) and 1\% PS for six days in 24-well plates at a density of $5 \times 10^{5}$ cells per well with $100 \mathrm{ng} /$ $\mathrm{mL}$ granulocyte macrophage colony-stimulating factor (LG Biochemical, Daejeon, Korea) and 20 ng/mL IL-4 (R\&D Systems, Minneapolis, MN, USA). On day six, the immature DCs were matured through the addition of a type 1-polarized DC $(\alpha \mathrm{DC} 1)$ cocktail containing IL-1 $\beta$ (25 ng/mL), TNF- $\alpha$ (50 ng/mL), IFN- $\alpha(3,000 \mathrm{U} /$ $\mathrm{mL}$, Intron-A-IFN- $\alpha-2 b$; Schering-Plough), IFN- $\gamma(1,000$ $\mathrm{U} / \mathrm{mL}$; Strathmann Biotech) and Poly (I:C) $(20 \mu \mathrm{g} / \mathrm{mL}$; Sigma-Aldrich). The $\alpha \mathrm{DC} 1 \mathrm{~s}$ were harvested on day eight.

\section{Peptide binding assay}

The T2 cell line was used to evaluate the binding affinity of a multipeptide cocktail of the three selected HLA-A*0201 peptides - ERBB2 ${ }_{369}$ (KIFGSLAFL),

Table 1: Peptide sequence as predicted by BIMAS

\begin{tabular}{lccc}
\hline Peptide & Start Position & $\begin{array}{c}\text { Subsequence Residue } \\
\text { Listing }\end{array}$ & Score \\
\hline ERBB2 & 369 & KIFGSLAFL & 481 \\
& 106 & QLFEDNYAL & 324 \\
& 689 & RLQETTELV & 126 \\
& 789 & CLTSTVQLV & 159 \\
BIRC5 & 5 & TLPPAWQPEL & Reference [28] \\
& 95 & ELTGEFLKL & Reference [29] \\
& 96 leucine & LLLGEFLKL & Reference [30] \\
& 96 methionine & LMLGEFLKL & Reference [30] \\
CD99 & 9 & LLLFGLLGV & 1006 \\
& 6 & ALALLLFGL & 284 \\
& 13 & GLLGVLVAA & 42 \\
& 10 & LLFGLLGVL & 16 \\
\hline
\end{tabular}

(Score: Estimate of half time of disassociation of a molecule containing this subsequence) 
BIRC5 $_{96 \text { methionine }}$ (LMLGEFLKL) and CD99 (LLLFGLLGV). In brief, T2 cells were pulsed overnight with the multipeptide cocktail or branched multipeptide (at a total concentration of $0,7.5,15.0,22.5$, or $30.0 \mu \mathrm{g} /$ $\mathrm{mL}$ ) plus $3 \mu \mathrm{g} / \mathrm{mL}$ human $\beta 2$-microglobulin (Sigma, USA). Following incubation, the cells were stained with an antihuman HLA-A2-FITCmAb (BB7.2; AbCam) and analyzed with a FACSCalibur flow cytometer (Becton Dickinson) and Win MDI version 2.9 (BioSoftNet). HLA-A2 expression was quantified according to the following formula: [(mean fluorescence with the peptide - mean fluorescence without the peptide) / mean fluorescence without the peptide] $\times 100$. No peptide was used as a negative control, and WT- $1_{126}$ (RMFPNAPYL) was used as an HLA-A2-specific positive control. The values represent the MFI. Results are reported as mean values $\pm \mathrm{SE}$ of three separate experiments.

\section{Peptide stability assay}

The multipeptide cocktail was examined for HLA-A2 stability. Briefly, T2 cells were pulsed overnight with the multipeptide cocktail or branched multipeptide $(22.5 \mu \mathrm{g} / \mathrm{mL})$ plus $3 \mu \mathrm{g} / \mathrm{mL}$ human $\beta 2$-microglobulin. For the measurement of the peptide/HLA-A2 complex stability, cells were stained with BB7.2 at 0,2, 4, 8 and 24 hours after treatment with BFA, and then were analyzed by flow cytometry. Results are reported as mean values \pm SE of three separate experiments.

\section{Immunophenotyping of DCs}

Phycoerythrin- or FITC-conjugated mAbs were added to the cell pellets, which were then incubated for $30 \mathrm{~min}$ on ice and washed three times before analysis. Mature $\alpha \mathrm{DC} 1 \mathrm{~s}$ were stained with phycoerythrin-conjugated $\mathrm{mAbs}$ against CD80 and CD86. Moreover, DCs were stained with FITCconjugated mAbs against CD83 and CCR7. DC phenotypes were assayed with a FACSCalibur flow cytometer, and the data were analyzed in Win MDI version 2.9. ERBB2, BIRC5 and CD99 individual peptide-pulsed $\alpha \mathrm{DC} 1 \mathrm{~s}$ were termed as "A,B,C-pulsed $\alpha \mathrm{DC} 1 \mathrm{~s}$," while mixed ERBB2, BIRC5 and $\mathrm{CD} 99$ peptide-pulsed $\alpha \mathrm{DC} 1 \mathrm{~s}$ were termed as " $\mathrm{A} / \mathrm{B} / \mathrm{C}$ pulsed $\alpha \mathrm{DC} 1 \mathrm{~s}$," and branched multipeptide-pulsed $\alpha \mathrm{DC} 1 \mathrm{~s}$ were termed as "Branched multipeptide-pulsed $\alpha \mathrm{DC} 1 \mathrm{~s}$ " (A: ERBB2, B: BIRC5, C: CD99). Based on the isotypematched negative controls, the results are reported as mean $\mathrm{MFI}$ values $\pm \mathrm{SE}$ of three separate experiments.

\section{Cytokine analysis by enzyme-linked immunosorbent assay (ELISA)}

The levels of IL-12p40, IL-12p70, IL-10 and IL-23 in the primary culture supernatants of DCs were measured with Quantikine Immunoassay Kits (R\&D Systems). In addition, the DCs harvested on day eight were plated in 96-well plates at a density of $2 \times 10^{4}$ cells per well, and cytokine secretion was stimulated through the use of CD40 ligand (CD40L)-transfected J558 cells (as an analog of CD40L-expressing Th cells; a kind gift from Dr. P. Lane, University of Birmingham, UK) at a density of $5 \times 10^{4}$ cells per well. After 24 hours, the supernatant was harvested, and cytokine production was determined by ELISA. Each sample was analyzed in triplicate and the mean absorbance for each set of standards and samples was calculated.

\section{ELISPOT}

The ELISPOT assay for the enumeration of antigenspecific IFN- $\gamma$-secreting cells was performed as indicated by the manufacturer (BD Biosciences).

We cultured effector CTLs, and either mixed them with ERBB2, BIRC5 and CD99 individual peptide-pulsed $\alpha \mathrm{DC} 1 \mathrm{~s}$ and stimulated them with autologous $\mathrm{CD}^{+} \mathrm{T}$ cells (termed as "A,B,C DC-CTLs"); mixed them with ERBB2, BIRC5 and CD99 peptide-pulsed $\alpha \mathrm{DC} 1 \mathrm{~s}$ and stimulated them with $\mathrm{CD}^{+} \mathrm{T}$ cells (termed as "A/B/C DC-CTLs"); or mixed them with branched multipeptide-pulsed $\alpha \mathrm{DC} 1 \mathrm{~s}$ and stimulated them with $\mathrm{CD} 3^{+} \mathrm{T}$ cells (termed as "Branched DC-CTLs").

T2 cells pulsed with the multipeptide cocktail were used as target cells for IFN- $\gamma$ ELISPOT assay. These included $\mathrm{T} 2$ cells individually pulsed with the ERBB2, BIRC5 and CD99 peptides (termed as "A,B,C T2") and T2 cells pulsed with mixed ERBB2, BIRC5 and CD99 peptides (termed as "A/B/C T2"). Branched multipeptidepulsed T2 cells (termed as "Branched T2") were also used as target cells. Unpulsed T2 cells (termed as "Unpulsed T2") were used as a negative control, and HIV-1 gp160 (KLTPLCVTL)-pulsed T2 cells (termed as "HIV T2") were used as an irrelevant control.

Further, the glioblastoma cell lines U87, U251 and U343 were used as target cells.

The number of IFN- $\gamma$ spots was enumerated by an automatic CTL Immunospot Analyzer (Cellular Technology Ltd., Shaker Heights, OH, USA). All samples were run in triplicate, and the data are expressed as the mean number of spots $\pm \mathrm{SD}$ per $10^{5} \mathrm{CD} 8^{+} \mathrm{T}$ cells.

\section{LDH release cytotoxicity assay}

The CytoTox 96 nonradioactive cytotoxicity assay (Promega, USA) was performed to measure the cytotoxic activity of CTLs according to the manufacturer's instructions. The effector cells were made with different combinations of the three peptides. Briefly, we cultured effector CTLs including A,B DC-CTLs, B,C DC-CTLs, A,C DC-CTLs, A,B,C DC-CTLs and Branched DC-CTLs. As for the target cells, U251 and primary glioblastoma cells $\left(1 \times 10^{5} \mathrm{cells} /\right.$ well $)$ were added to 96 -well uncoated plates (Costar, USA). The effector CTLs were added at an $\mathrm{E} / \mathrm{T}$ ratio of 10:1. The W6/32 monoclonal antibody (mAb; a gift from Dr. Bin Gao, ICH, London, United Kingdom) 
was used to block MHC class I antigen presentation on U251 and primary glioblastoma cells. Cells were washed twice with PBS and then incubated with the W6/32 mAb $(1 \mu \mathrm{g} / \mathrm{mL})$ on ice for one hour. The cells were then washed and used in cytotoxicity assays.

The spontaneous lactate dehydrogenase (LDH) release measurements of control groups of effector cells and target cells, the maximum LDH release measurements of target cells, the volume correction control and the culture medium background correction were performed at the same time. The plates were incubated for four hours in a humidified chamber at $37^{\circ} \mathrm{C}$ and $5 \% \mathrm{CO} 2$, then centrifuged at $250 \times g$ for five minutes. Aliquots $(50 \mu \mathrm{L})$ were transferred from all wells to fresh 96-well flat-bottom plates, and an equal volume of reconstituted substrate mix was added to each well. The plates were incubated at room temperature for $30 \mathrm{~min}$ and protected from light. Then, $50 \mathrm{~mL}$ of stop solution was added, and the absorbance values were measured at $492 \mathrm{~nm}$. The mean percentage of specific lysis in triplicate wells was calculated as follows: $\%$ Cytotoxicity $=($ Experimental - Effector Spontaneous - Target Spontaneous) / (Target Maximum - Target Spontaneous) $\times 100$.

\section{Statistical analysis}

All statistical analyses were performed with SPSS 13.0 for Windows (SPSS Inc., Chicago, IL, USA). Oneway analysis of variance (ANOVA) was performed to analyze the statistical significance of non-parametric differences between the groups. $\mathrm{P}<0.05$ was considered statistically significant.

\section{ACKNOWLEDGMENTS}

This study was supported by the Basic Science Research Program through the National Research Foundation of Korea (NRF), funded by the Ministry of Science, ICT, \& Future Planning (2014R1A1A1004469).

\section{CONFLICTS OF INTEREST}

The authors report no conflicts of interest. The authors alone are responsible for the content and writing of the paper.

\section{REFERENCES}

1. Parney IF, Hao C and Petruk KC. Glioma immunology and immunotherapy. Neurosurgery. 2000; 46:778-791.

2. Stupp R, Mason WP, van den Bent MJ, Weller M, Fisher B, Taphoorn MJ, Belanger K, Brandes AA, Marosi C, Bogdahn U, Curschmann J, Janzer RC, Ludwin SK, et al. Radiotherapy plus concomitant and adjuvant temozolomide for glioblastoma. N Engl J Med. 2005; 352:987-996.
3. Han SJ, Englot DJ, Birk H, Molinaro AM, Chang SM, Clarke JL, Prados MD, Taylor JW, Berger MS and Butowski NA. Impact of Timing of Concurrent Chemoradiation for Newly Diagnosed Glioblastoma: A Critical Review of Current Evidence. Neurosurgery. 2015; 62:160-165.

4. Akiyama Y, Oshita C, Kume A, Iizuka A, Miyata H, Komiyama M, Ashizawa T, Yagoto M, Abe Y, Mitsuya K, Watanabe R, Sugino T, Yamaguchi K, et al. alpha-type-1 polarized dendritic cell-based vaccination in recurrent highgrade glioma: a phase I clinical trial. BMC cancer. 2012; 12:623.

5. Okada H, Kalinski P, Ueda R, Hoji A, Kohanbash G, Donegan TE, Mintz AH, Engh JA, Bartlett DL, Brown CK, Zeh H, Holtzman MP, Reinhart TA, et al. Induction of CD8+ T-cell responses against novel glioma-associated antigen peptides and clinical activity by vaccinations with \{alpha\}-type 1 polarized dendritic cells and polyinosinic-polycytidylic acid stabilized by lysine and carboxymethylcellulose in patients with recurrent malignant glioma. J Clin Oncol. 2011; 29:330-336.

6. Pollack IF, Jakacki RI, Butterfield LH, Hamilton RL, Panigrahy A, Potter DM, Connelly AK, Dibridge SA, Whiteside TL and Okada H. Antigen-specific immune responses and clinical outcome after vaccination with glioma-associated antigen peptides and polyinosinic-polycytidylic acid stabilized by lysine and carboxymethylcellulose in children with newly diagnosed malignant brainstem and nonbrainstem gliomas. J Clin Oncol. 2014; 32:2050-2058.

7. Yu JS, Wheeler CJ, Zeltzer PM, Ying H, Finger DN, Lee PK, Yong WH, Incardona F, Thompson RC, Riedinger MS, Zhang W, Prins RM and Black KL. Vaccination of malignant glioma patients with peptide-pulsed dendritic cells elicits systemic cytotoxicity and intracranial T-cell infiltration. Cancer Res. 2001; 61:842-847.

8. Banchereau J and Steinman RM. Dendritic cells and the control of immunity. Nature. 1998; 392:245-252.

9. Hoppes R, Oostvogels R, Luimstra JJ, Wals K, Toebes M, Bies L, Ekkebus R, Rijal P, Celie PH, Huang JH, Emmelot ME, Spaapen RM, Lokhorst H, et al. Altered peptide ligands revisited: vaccine design through chemically modified HLA-A2-restricted T cell epitopes. J Immunol. 2014; 193:4803-4813.

10. Mateo L, Gardner J, Chen Q, Schmidt C, Down M, Elliott SL, Pye SJ, Firat H, Lemonnier FA, Cebon J and Suhrbier A. An HLA-A2 polyepitope vaccine for melanoma immunotherapy. J Immunol. 1999; 163:4058-4063.

11. Toes RE, Offringa R, Blom RJ, Melief CJ and Kast WM. Peptide vaccination can lead to enhanced tumor growth through specific T-cell tolerance induction. Proc Natl Acad Sci U S A. 1996; 93:7855-7860.

12. Liu G, Ying H, Zeng G, Wheeler CJ, Black KL and Yu JS. HER-2, gp100, and MAGE-1 are expressed in human glioblastoma and recognized by cytotoxic $\mathrm{T}$ cells. Cancer Res. 2004; 64:4980-4986. 
13. Murayama K, Kobayashi $\mathrm{T}$, Imaizumi $\mathrm{T}$, Matsunaga K, Kuramoto T, Shigemori M, Shichijo S and Itoh K. Expression of the SART3 tumor-rejection antigen in brain tumors and induction of cytotoxic $\mathrm{T}$ lymphocytes by its peptides. J Immunol. 2000; 23:511-518.

14. Tsuda N, Nonaka Y, Shichijo S, Yamada A, Ito M, Maeda Y, Harada M, Kamura T and Itoh K. UDP-Gal: betaGlcNAc beta1, 3-galactosyltransferase, polypeptide 3 (GALT3) is a tumour antigen recognised by HLA-A2-restricted cytotoxic $\mathrm{T}$ lymphocytes from patients with brain tumour. $\mathrm{Br} \mathrm{J}$ Cancer. 2002; 87:1006-1012.

15. Zhang JG, Eguchi J, Kruse CA, Gomez GG, Fakhrai H, Schroter S, Ma W, Hoa N, Minev B, Delgado C, Wepsic HT, Okada H and Jadus MR. Antigenic profiling of glioma cells to generate allogeneic vaccines or dendritic cell-based therapeutics. Clin Cancer Res. 2007; 13:566-575.

16. Zhang JG, Kruse CA, Driggers L, Hoa N, Wisoff J, Allen JC, Zagzag D, Newcomb EW and Jadus MR. Tumor antigen precursor protein profiles of adult and pediatric brain tumors identify potential targets for immunotherapy. J Neurooncol. 2008; 88:65-76.

17. Jung TY, Choi YD, Kim YH, Lee JJ, Kim HS, Kim JS, Kim SK, Jung S and Cho D. Immunological characterization of glioblastoma cells for immunotherapy. Anticancer Res. 2013; 33:2525-2533.

18. Wang GZ, Tang XD, Lu MH, Gao JH, Liang GP, Li N, Li CZ, Wu YY, Chen L, Cao YL, Fang DC and Yang SM. Multiple antigenic peptides of human heparanase elicit a much more potent immune response against tumors. Cancer Prev Res (Phila). 2011; 4:1285-1295.

19. Varasteh Z, Rosenstrom U, Velikyan I, Mitran B, Altai M, Honarvar H, Rosestedt M, Lindeberg G, Sorensen J, Larhed M, Tolmachev V and Orlova A. The effect of miniPEG-based spacer length on binding and pharmacokinetic properties of a 68Ga-labeled NOTA-conjugated antagonistic analog of bombesin. Molecules. 2014; 19:10455-10472.

20. Chung HY, Yoon JA, Han BY, Song EY and Park MH. [Allelic and haplotypic diversity of HLA-A, -B, -C, and -DRB1 genes in Koreans defined by high-resolution DNA typing]. Korean J Lab Med. 2010; 30:685-696.

21. Autio A, Henttinen T, Sipila HJ, Jalkanen S and Roivainen A. Mini-PEG spacering of VAP-1-targeting
68Ga-DOTAVAP-P1 peptide improves PET imaging of inflammation. EJNMMI Res. 2011; 1:10.

22. Morford LA, Dix AR, Brooks WH and Roszman TL. Apoptotic elimination of peripheral $\mathrm{T}$ lymphocytes in patients with primary intracranial tumors. J Neurosurg. 1999; 91:935-946.

23. Kikuchi T, Akasaki Y, Irie M, Homma S, Abe T and Ohno $\mathrm{T}$. Results of a phase I clinical trial of vaccination of glioma patients with fusions of dendritic and glioma cells. Cancer Immunol Immunother. 2001; 50:337-344.

24. Yamanaka R, Abe T, Yajima N, Tsuchiya N, Homma J, Kobayashi T, Narita M, Takahashi M and Tanaka R. Vaccination of recurrent glioma patients with tumour lysatepulsed dendritic cells elicits immune responses: results of a clinical phase I/II trial. Br J Cancer 2003; 89:1172-1179.

25. Dutoit V, Herold-Mende C, Hilf N, Schoor O, Beckhove P, Bucher J, Dorsch K, Flohr S, Fritsche J, Lewandrowski P, Lohr J, Rammensee HG, Stevanovic S, et al. Exploiting the glioblastoma peptidome to discover novel tumourassociated antigens for immunotherapy. Brain. 2012; 135:1042-1054.

26. Uhlén M, Fagerberg L, Hallström BM, Lindskog C, Oksvold P, Mardinoglu A, Sivertsson Å, Kampf C, Sjöstedt E, Asplund A, Olsson I, Edlund K, Lundberg E, et al. Proteomics. Tissue-based map of the human proteome. Science. 2015; 347:1260419.

27. Bossi G, Gerry AB, Paston SJ, Sutton DH, Hassan NJ and Jakobsen BK. Examining the presentation of tumor-associated antigens on peptide-pulsed T2 cells. Oncoimmunology. 2013; 2:e26840.

28. Liu R and Mitchell DA. Survivin as an immunotherapeutic target for adult and pediatric malignant brain tumors. Cancer Immunol Immunother. 2010; 59:183-193.

29. Andersen MH, Pedersen LO, Becker JC and Straten PT. Identification of a cytotoxic $\mathrm{T}$ lymphocyte response to the apoptosis inhibitor protein survivin in cancer patients. Cancer Res. 2001; 61:869-872.

30. Siegel S, Steinmann J, Schmitz N, Stuhlmann R, Dreger $\mathrm{P}$ and Zeis $\mathrm{M}$. Identification of a survivinderived peptide that induces HLA-A*0201-restricted antileukemia cytotoxic T lymphocytes. Leukemia. 2004; 18:2046-2047. 